\title{
New avenues for increasing yield and stability in C3 cereals: exploring ear photosynthesis Rut Sanchez-Bragado ${ }^{a, b}$, Rubén Vicente ${ }^{c}$, Gemma Molero ${ }^{d}$, Maria Dolors Serret ${ }^{\mathrm{b}}$, María Luján Maydup ${ }^{\mathrm{e}}$ and José Luis Araus ${ }^{\mathrm{b}}$
}

\begin{abstract}
Small grain cereals such as wheat, rice and barley are among the most important crops worldwide. Any attempt to increase crop productivity and stability through breeding implies developing new strategies for plant phenotyping, including defining ideotype attributes for selection. Recently, the role of non-foliar photosynthetic organs, particularly the inflorescences, has received increasing attention. For example, ear photosynthesis has been reported to be a major contributor to grain filling in wheat and barley under stress and good agronomic conditions. This review provides an overview of the particular characteristics of the ear that makes this photosynthetic organ better adapted to grain filling than the flag leaf and revises potential metabolic and molecular traits that merit further research as targets for cereal improvement. Currently, the absence of highthroughput phenotyping methods limits the inclusion of ear photosynthesis in the breeding agenda. In this regard, a number of different approaches are presented.
\end{abstract}

\footnotetext{
Addresses

${ }^{a}$ Department of Crop and Forest Sciences, University of Lleida AGROTECNIO Center, Av. R. Roure 191, 25198 Lleida, Spain

${ }^{\mathrm{b}}$ Secció de Fisiologia Vegetal, Facultat de Biologia, Universitat de Barcelona, Barcelona, and AGROTECNIO Center, Lleida, Spain

${ }^{\mathrm{C}}$ Max Planck Institute of Molecular Plant Physiology, Am Mühlenberg 1, 14476 Potsdam, Germany

${ }^{\mathrm{d}}$ Global Wheat Program, International Maize and Wheat Improvement Centre (CIMMYT), Texcoco, Mexico

${ }^{e}$ National Council of Scientific and Technological Research, CONICET, La Plata University- Plant Physiology Institute INFIVE, Argentina

Corresponding author: Araus, José Luis (jaraus@ub.edu)
}

Current Opinion in Plant Biology 2019, xx:xx-yy

This review comes from a themed issue on AGRI

Edited by David Edwards

https://doi.org/10.1016/j.pbi.2020.01.001

1369-5266/৫ 2020 Elsevier Ltd. All rights reserved.

\section{Introduction}

The main staple crops at a global level are wheat followed by rice, while other small grain cereals such as barley are also among the most cultivated. Annual genetic gains for wheat have been reported as $\sim 1 \%$ on average [1,2] not sufficient to meet the projected global demand, which increases by $1.7 \%$ annually [3]. Indeed, progress from the main traits that contributed to the Green Revolution, such as harvest index, have become exhausted. Therefore, yield improvements will need to come from technological innovations together with new traits not considered before.

Climate change predictions for the coming decades include increases in temperature as well as longer and more numerous droughts in many regions, which together with other global change challenges (demography, dietary habits, etc.), demand increases to the productivity and stability of wheat. Increasing the photosynthetic efficiency of leaves, which frequently includes genetically modified organisms (GMO) approaches, has been argued as one of the logical avenues to tackle the problem and achieve the so-called second 'Green Revolution'. However, in spite of the abundant literature produced [4,5], gene transformation approaches have not yet delivered their promise [6]. In fact, the most solid evidence related to an increase in yield being associated with increases in photosynthesis originates from retrospective studies where genetic advances in photosynthesis have been paralleled by increases in stomatal conductance [7], while in other cases stay-green is the main factor [8]. However, in some cases, like durum wheat under Mediterranean conditions, stay green has not necessarily been a positive trait [9].

In any case, rather than individual processes such as the photosynthetic capacity of single leaves, it is likely that the integrated canopy photosynthesis may be more relevant for determining final yield [10]. Canopy photosynthesis is not only dependent on the photosynthesis of individual leaves but also on the non-laminar parts, including reproductive organs such as the ears or the panicles when cereals are considered.

\section{Ear photosynthesis and grain filling}

Surprisingly, the photosynthetic contribution of nonlaminar parts and particularly of the inflorescence (the ear in the case of wheat or barley, and the panicle for rice or oats) has been barely considered. In fact, grain set and further filling occurs by acquisition of 
assimilates from (i) flag leaf photosynthesis (blades and sheaths), (ii) ear photosynthesis and (iii) remobilisation of assimilates stored in the stem (mostly) before anthesis $\left[11,12^{\bullet \bullet}\right]$. The contribution of each component depends on the plant species, cultivar and environment. However, different lines of evidence, including diverse methodological approaches, have concluded that the ear may be the main contributor to grain filling. Methodological approaches include not only disrupting treatments, consisting of specific elimination of the photosynthetic activity of the ear, the leaves or other parts of the plant $\left[13^{\bullet}, 14^{\circ}\right]$ but also using non-disruptive approaches $[15,16]$. Moreover, by using measurements of $\mathrm{N}$ content and the natural abundance of $\delta^{15} \mathrm{~N}$, a potential contribution of ears in providing $\mathrm{N}$ has been determined in wheat, and it is at least similar to the contribution of leaves and even more relevant under water-limiting and nitrogen-limiting conditions [17]. Accordingly, Lopes et al. [18] proved that glumes participate in the storage and remobilisation of $\mathrm{N}$ to the grain.

The net photosynthesis rate on a per unit area basis in the ear is considerably lower than that of leaves (flag and penultimate leaf). However, its real photosynthetic importance may in fact be underestimated by the high rates of respiration of the ear [19]. The high rates of respiration in the ear are due to the presence of heterotrophic tissues and the respiration of the developing grains $\left[12^{\bullet \bullet}, 20^{\circ}\right]$. Overall the photosynthetic capacity of the ear as a whole organ may reach values close [21 ${ }^{\circ}$ or even higher to that of the flag leaf $[19,24]$. Moreover, while wheat leaf photosynthesis declines after anthesis, other organs such as the ear, stem and leaf sheath may remain comparatively photosynthetically active during the second half of grain filling, contributing photoassimilates to growing grains [ $\left.22^{\circ}\right]$. Because of its proximity to developing grains and its continuing photosynthetic capacity during grain filling, the ear seems to be one of the main photosynthetic contributors during grain filling $\left[13^{\bullet \bullet}, 20^{\bullet}, 22^{\bullet}, 23\right]$. In fact, theoretical capacity of the ear to produce assimilates along the grain filling equates the total weight of the grains in the ear $\left[14^{\circ}\right]$. However, although a positive relationship has been reported between ear photosynthesis and grain yield in wheat $[11,24]$, no clear links have been found in retrospective studies between the genetic advance in grain yield and ear photosynthesis $\left[13^{\bullet \bullet}, 25\right]$.

It has been proposed in wheat using $\mathrm{C}$ isotope composition, among other methodologies, that the $\mathrm{C}$ assimilated by flag leaves is mainly used for shoot growth [26], while a significant part of the $\mathrm{C}$ (and $\mathrm{N}$ ) accumulated in grains of wheat, barley and rice comes from the ears and panicles when good agronomic conditions exist $[16,26,27]$. This is even more relevant under water-limiting and N-limiting conditions $\left[11,15-17,20^{\circ}, 28\right]$.
Altogether, the photosynthetic contribution of inflorescences in $\mathrm{C}_{3}$ cereals is a key factor for grain yield during grain filling, and this is especially so under heat-stress and water-stress conditions that will be more frequent and more severe with climate change in the Mediterranean basin. For example, in the case of wheat, different transcriptomic, metabolomic and physiological approaches show that the ears are more stress resistant than the leaves $\left[2^{\circ}\right.$ ] . However, recent evidence indicates that the contribution of ear photosynthesis to grain filling may also be important under good agronomic conditions $\left[13^{\bullet \bullet}, 14^{\bullet}, 15,16\right]$. These aspects make ear photosynthesis an important target for increasing yield potential and stability. The particular characteristics of the ear as a photosynthetic organ may confer some advantages compared to the flag leaf and the rest of foliar canopy $\left[12^{\bullet \bullet}\right]$.

A recent study has identified several QTLs associated with ear photosynthesis including a common QTL for yield potential and heat stress on chromosome $5 \mathrm{~B}$ in a mapping population developed from a cross between durum and emmer wheat [30]. The QTLs identified for ear photosynthesis in the cited study co-located with previous QTLs identified for yield, grain weight, grain number, root traits and photochemical reflectance index, and confirmed the contribution of ear photosynthesis to these traits at a genetic level.

\section{The ear is a 'constitutively' stress-adapted organ}

Ears have evolved under full exposure to solar radiation, unlike the rest of the canopy. In the case of wheat, ears intercept up to $30 \%$ of the incident radiation [16], and in the case of two row barley with its prostrated ears probably far more (Figure 1). Moreover, because of its apical position, the ear is far less susceptible to possible shading events in front of frequent fluctuations of light caused by wind-induced movements [31] compared with wheat leaves [32]. Excessive light absorption by the ears may be mitigated by the presence of epicuticular waxes, which in this organ have a special structure favouring the reflectance of radiation [33], and in the case of awned ears, the awns diffuse the incoming light. Nevertheless, regardless of the water regime, under sunny conditions ears may exhibit temperatures that are several degrees higher than the flag leaves or the rest of the canopy [29 $\left.9^{\bullet}\right]$.

Ear photosynthesis, including Rubisco, chlorophylls, chlorophyll fluorescence parameters and stomatal conductance, is less adversely affected by drought than leaves $\left[34,35^{\bullet}, 36,37\right]$, even considering that under such conditions the ear temperature may be several degrees higher than the leaves (Figure 2). Interestingly, awns have more heat-stable photosynthesis and a higher optimum temperature than flag leaves [38]. Additionally, ear organs exhibit delayed senescence $\left[12^{\bullet \bullet}, 22^{\bullet}, 29^{\bullet \bullet}, 35^{\circ}\right]$. Therefore, ear photosynthesis may 
Ear photosynthesis in crop breeding Sanchez-Bragado et al. 3

Figure 1

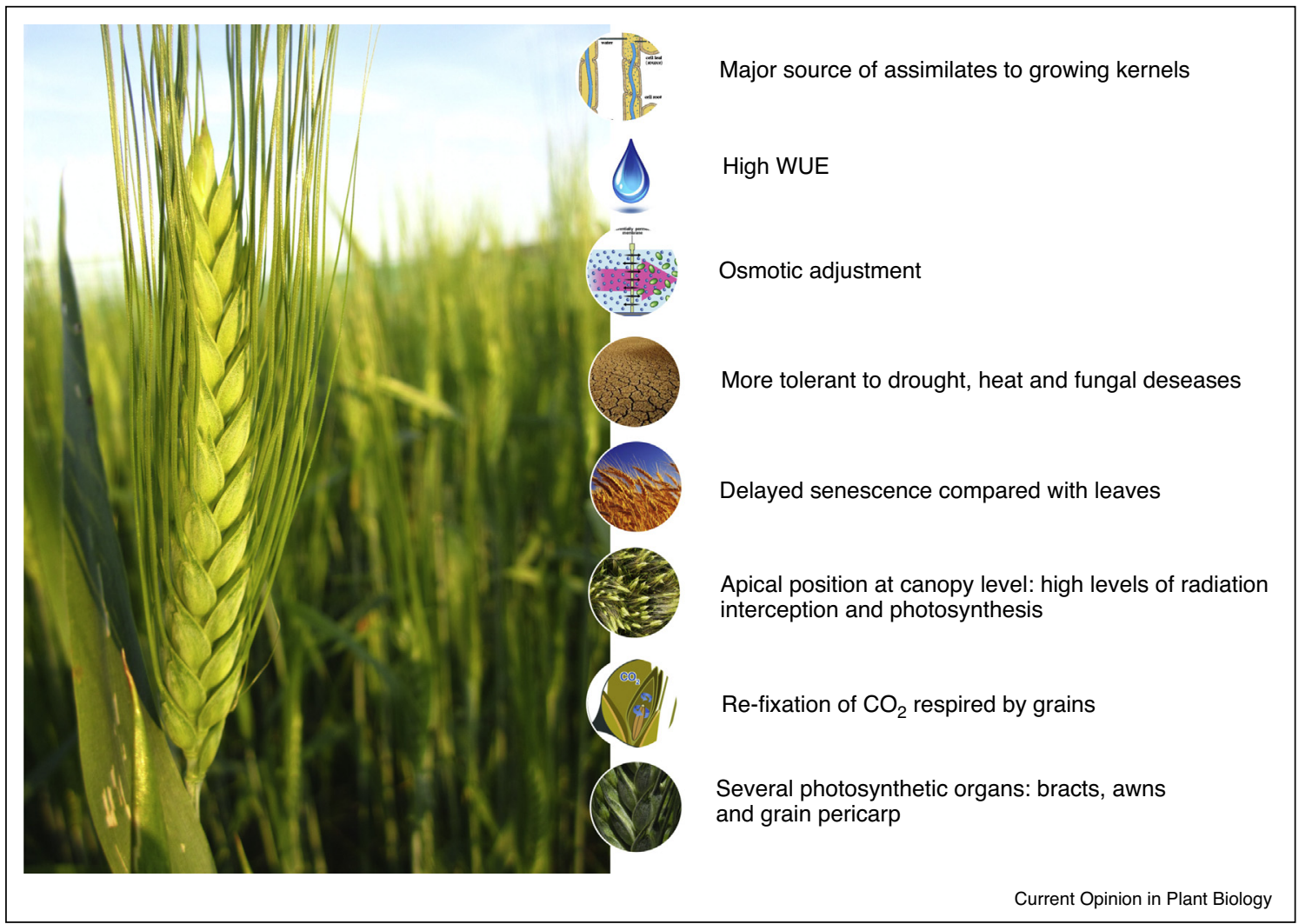

The particular physiological and morphological characteristics of the ear makes this organ especially advantageous, not only under drought and heat conditions but also under good agronomic conditions: (i) the proximity to the sink organs facilitates the transport of assimilates compared to other source organs; the xeromorphic anatomy of the ears, together with (vii) the re-fixation of $\mathrm{CO}_{2}$ respired by grains may grant the ear (ii) a higher water use efficiency (WUE) $\left[20^{\circ}, 24\right]$, which combined with (iii) a higher osmotic adjustment [37] provides greater capacity to maintain higher relative water content with respect to the rest of the plant [39,75]. As a consequence, this may avoid dehydration of the bracts and awns [76] therefore preventing (iv-v) drought or heat-induced senescence compared to the flag leaves [37] or the incidence of certain fungal diseases that can affect the leaves much more than the ears $[76,77]$. The ear (vi) is the organ with the greatest exposure to radiation due to its apical position in the plant, and consequently it experiences the most heat, increasing respiration losses. Nevertheless, the excessive light absorption may be mitigated by the presence of epicuticular waxes [33]. The refixation of $\mathrm{CO}_{2}$ (vii) respired by the growing grains is another characteristic that makes the ear photosynthesis different from that of the leaves [20\%. In fact (viii) the awns and external surfaces of the glumes are considered the main photosynthetic organs in ears fixing external $\mathrm{CO}_{2}$, whereas internal surfaces of ear bracts (i.e. lemmas and paleae) and the green pericarp probably have a role more closely related to recycling $\mathrm{CO}_{2}$ respired by the grains $\left[12^{\bullet \bullet}, 29^{\bullet \bullet}, 41,78\right]$.

have special morphological, physiological and metabolic features that confer tolerance to heat and water stress more than other parts of the plant.

Ears exhibit better performance under water stress than leaves due to better nitrogen and water status, photochemical efficiency, stability of the photosynthetic apparatus, lower diffusive conductance, and high expression of key genes for primary metabolism as well as for droughtstress responses $\left[29^{\bullet \bullet}, 36\right]$. Better water status in ear bracts and awns under water stress has been correlated with higher osmotic adjustment and a higher Relative Water Content (RWG) compared to the leaves [20, $37-39]$. Osmotic adjustment (accumulation of osmolytes) can ensure maintenance of turgor and gas exchange under water stress [37]. These drought tolerance traits are related to the xeromorphic anatomy of ear, which exhibits thick epidermis and cuticle on the dorsal side of bracts $\left[20^{\bullet}, 36,40\right]$. Moreover, because of the excess light intercepted (more than needed for photosynthesis) and the presence of high temperatures, ears exhibit higher nonphotochemical quenching (NPQ) and xanthophyll cycledependent photoprotection than leaves to dissipate the excess energy and heat and thus protect the photosynthetic apparatus $\left[35^{\circ}\right]$. In fact, the chloroplasts in ears remain more structurally preserved than leaves under water stress $\left[35^{\circ}\right]$.

Because of their anatomy and proximity to respired $\mathrm{CO}_{2}$ released during grain endosperm respiration, ear bracts 


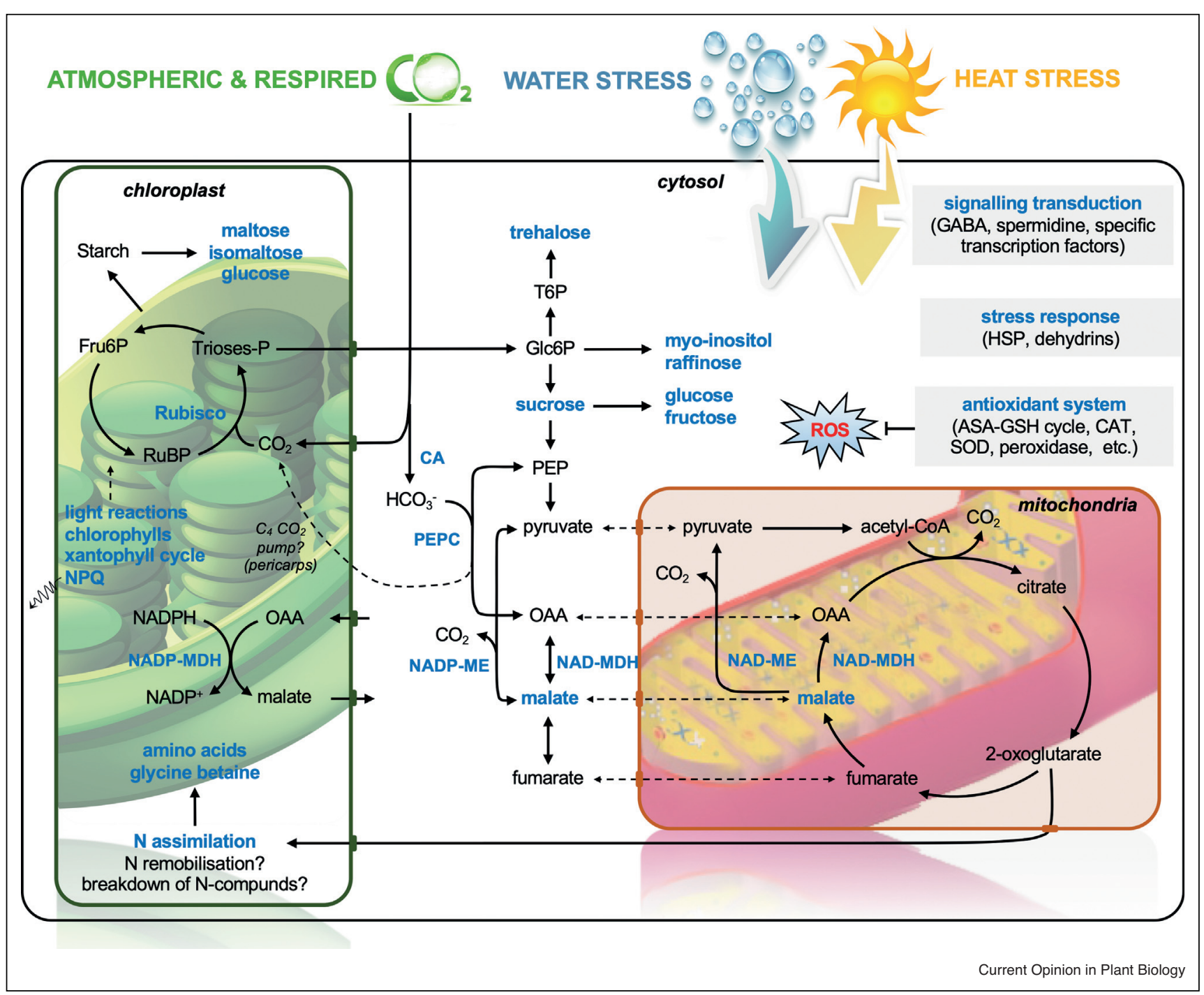

Overview of the most relevant changes observed in ear organs under water and/or heat stress. The components and processes that showed upregulation (in terms of either higher content, activity or gene expression) and/or better performance (i) in ears compared to leaves or (ii) in ears under water stress compared to optimal conditions are highlighted in blue. However, under water stress a lower accumulation of ROS was observed in ears compared to leaves (highlighted in red) $\left[22^{\bullet}, 29^{\bullet}, 35^{\circ}, 36,44,46,47^{\bullet \bullet}, 52^{\bullet}, 53^{\circ \bullet}, 54^{\bullet \bullet}, 55^{\bullet}, 56^{\circ \bullet}, 57^{\circ}\right.$ ). These components are potential targets that can be used in breeding programmes to select genotypes not only possessing ears with better stress adaptation but eventually to improve the resilience of the whole plant to stress conditions in $\mathrm{C}_{3}$ cereals. The ear organs can fix $\mathrm{CO}_{2}$ more efficiently than leaves under stress conditions due to several factors, for example, their xeromorphic anatomy, better water status, greater uptake of respiratory $\mathrm{CO}_{2}$ from grains and delayed senescence. The proportion of atmospheric and respired $\mathrm{CO}_{2}$ used varies between organs and depends on their proximity to the developing grains and their different tolerance to stress conditions. Awns exhibit the highest photosynthetic capacity in ears and this is based on the uptake of atmospheric $\mathrm{CO}_{2}$. Although ear bracts can also fix atmospheric $\mathrm{CO}_{2}$ (mainly the glumes), a high capacity for the refixation of $\mathrm{CO}_{2}$ is

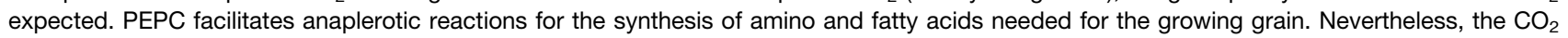
fixed by PEPC may be used via a " $\mathrm{C}_{4}$ pathway" in wheat pericarps to concentrate $\mathrm{CO}_{2}$ around Rubisco, although current evidences are very weak in this sense. Acetyl-CoA, acetyl coenzyme A; ASA-GSH, ascorbate-glutathione; CA, carbonic anhydrase; CAT, catalase; Fru6P, fructose 6phosphate; GABA, gamma-aminobutyric acid; Glc6P, glucose 6-phosphate; HSP, heat shock protein; MDH, malate dehydrogenase; ME, malic enzyme; NAD, nicotinamide adenine dinucleotide; NADP ${ }^{+}$NADPH, oxidised/reduced nicotinamide adenine dinucleotide; NPQ, non-photochemicalquenching; OAA, oxaloacetate; PEP, phosphoenolpyruvate; ROS, reactive oxygen species; Rubisco, RuBP carboxylase oxygenase; RuBP, ribulose-1,5-bisphophate; SOD, superoxide dismutase; T6P, trehalose 6-phosphate. 
Figure 3

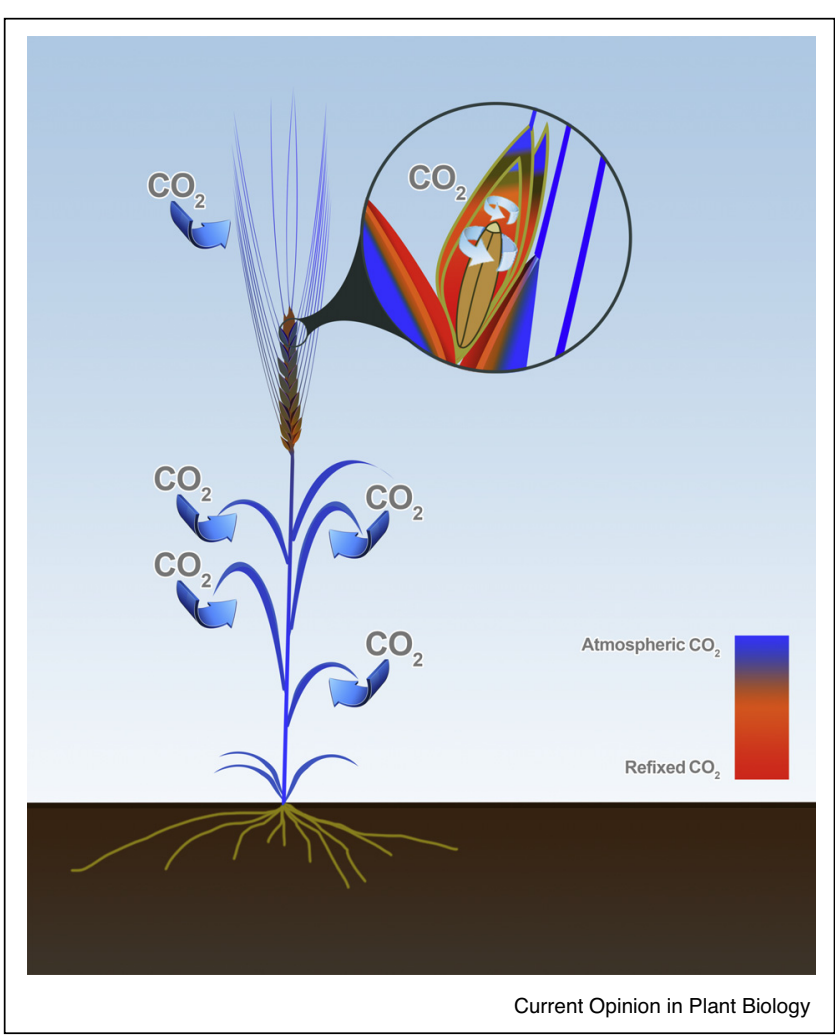

Provenance of the $\mathrm{CO}_{2}$ taken up by different organs in a wheat plant. Red represents organs and sites that mainly refix $\mathrm{CO}_{2}$ respired by developing grains, whereas blue represents organs and sites of net fixation of atmospheric $\mathrm{CO}_{2}$. The awns and the glumes (represented as blue in the figure) are putative sites for net fixation of atmospheric $\mathrm{CO}_{2}$ (stomata in these sites are abundant) [37]. By contrast, ear bracts (i.e. lemmas and paleae) and the green pericarps of the grains are mainly involved in recycling respiratory $\mathrm{CO}_{2}\left[12^{\circ \bullet}, 29^{\circ \bullet}, 41\right]$. Because of their anatomy and proximity to respired $\mathrm{CO}_{2}$ released during grain endosperm respiration, ear bracts and green pericarps exhibit a higher capacity for $\mathrm{CO}_{2}$ refixation (organs represented in red) than leaves and awns, which mainly fix atmospheric $\mathrm{CO}_{2}$ (organs represented in blue) $\left[12^{\bullet \bullet}, 40,41\right]$. This can reduce respiratory loss and increase the water use efficiency of the ear as a process independent of gas exchange.

and green pericarps show a higher capacity than leaves and awns for refixation of $\mathrm{CO}_{2}\left[12^{\bullet \bullet}, 40,41\right]$ (Figure 3). This can reduce respiratory losses and increase the water use efficiency of the ear as a process independent of gas exchange with the external atmosphere. Wheat and barley ears can refix $55-75 \%$ of the respired $\mathrm{CO}_{2}$ and this process can significantly contribute to grain yield [41-43]. When grains are bigger, they can block the stomata (ventral-side) of ear bracts and the uptake of $\mathrm{CO}_{2}$ from the atmosphere; however, this does not result in lower photosynthesis because there is compensation from the higher uptake of respiratory $\mathrm{CO}_{2}$ from grains and better exposure to light of the apical parts of the bracts after the spikelet structures are pushed apart by the growing grains $\left[12^{\bullet \bullet}, 40\right]$. High carbonic anhydrase (CA) activity was found in glumes, lemmas, paleae and pericarps during grain filling, which can catalyse the hydration of $\mathrm{CO}_{2}$ to $\mathrm{HCO}_{3}{ }^{-}$and provide the substrate for phosphoenolpyruvate carboxylase (PEPC) [44]. There exists a controversy about whether photosynthetic metabolism in ears is typically $\mathrm{C}_{3}$ or whether there is some degree of $\mathrm{C}_{4}, \mathrm{C}_{3}-\mathrm{C}_{4}$ intermediate or CAM, either constitutive or more apparent under drought conditions. $\mathrm{C}_{4}$ photosynthesis would provide clear advantages as an efficient form of carbon assimilation minimising carbon losses. Ziegler-Jons [45] proposed that wheat ear bracts exhibit an anatomy-like intermediate $\mathrm{C}_{3}-\mathrm{C}_{4}$, with the presence of a second type of cell surrounding the vascular bundles with evenly distributed chloroplasts, designated as bundle-sheath cells. Jia et al. [22 $2^{\circ}$ suggested that water deficit induced the activity of $\mathrm{C}_{4}$ pathway enzymes (PEPC; NADP-malate dehydrogenase, NADP-MDH; NAD(P)-malic enzyme, NAD(P)-ME; and pyruvate orthophosphate dikinase, PPDK) in ear bracts, especially in glumes and lemmas and during early grain filling, while at the same time Rubisco activity declined significantly (high PEPC/ Rubisco ratios). Supporting this, Singal et al. [46] showed that most of the $\mathrm{CO}_{2}$ fixed by ears in wheat was mainly accumulated in malate and $\mathrm{C}_{4}$ enzymes (i.e. PEPC, NAD (P)-MDH, NAD(P)-ME, aspartate aminotransferase and alanine aminotransferase), and the quantities of these were generally greater in ear organs than in flag leaves. Rangan et al. $\left[47^{\bullet \circ}\right.$ ] revealed that at the transcript level there is a complete set of specific $\mathrm{C}_{4}$ pathway enzymes in the pericarp of the developing wheat seed, and these are expressed at optimal levels during early to mid-grain filling. However, it is unlikely that $\mathrm{CAM}$ or $\mathrm{C}_{4}$ metabolism occur in ears (at least in the bracts) under optimal or water-limited conditions as has been demonstrated by (i) the $\mathrm{O}_{2}$ sensitivity of the assimilation rate and electron transport, (ii) the lack of Rubisco compartmentalisation in the mesophyll tissues and Kranz anatomy (although this is not strictly necessary), (iii) the gas-exchange pattern at night [37], (iv) the absence of any effect of a PEPC inhibitor on ear photosynthesis [48], (v) the low amounts of $\mathrm{C}_{4}$ acids (malate and aspartate) produced by photosynthesis [49], and (vi) the similarity of $\delta^{13} \mathrm{C}$ values in ear organs to other $\mathrm{C}_{3}$ plants $\left[20^{\circ}, 48\right]$. Moreover, immunolabelling studies suggest that PEPG is involved in anaplerotic reactions that supply four-carbon skeletons for the large demand for amino and fatty acids rather than the synthesis of carbohydrates in wheat grains [48,50], which is a conclusion that could be extended to the other $\mathrm{C}_{4}$ enzymes reported above. Nevertheless, whether $\mathrm{C}_{4}$ photosynthesis happens in wheat seeds is still a matter of debate [51] and further experimental evidence is required.

Osmolytes play an important role by maintaining cell turgor and preventing protein degradation and cells from oxidative damage by scavenging reactive oxygen species (ROS). Comparing ear organs in barley, Abebe et al. [52] 
showed that the effects of drought stress on gene expression were more evident in the awns, followed by lemmas and paleae, while little effect was observed in developing grains. Genes involved in the synthesis of osmolytes (proline, glycine betaine, spermidine, GABA, raffinose and trehalose) were upregulated under water stress. Moreover, alternative oxidase was reported as being upregulated in the lemmas, paleae, and awns, and this can reduce accumulation of ROS $\left[52^{\circ}\right]$. Genes for the drought stress response were upregulated in both wheat and barley ears $\left[29^{\bullet \bullet}, 52^{\circ}\right]$, including heat shock proteins, LEA (dehydrins), antioxidant system enzymes, and so on, which can play a role in stabilising proteins, preventing water loss and reducing ROS, among other functions.

Under water stress, Vicente et al. [29 $9^{\circ}$ ] observed an upregulation of genes involved in respiration, $\mathrm{CO}_{2}$ refixation via PEPC and nitrogen assimilation in glumes during the grain filling period, while genes related to light reactions and the Calvin-Benson cycle were less repressed than in leaves. Changes at the transcript level have been corroborated for metabolite and enzyme activities. Metabolome analysis of durum wheat leaves and ear bracts showed that respiratory intermediates and most amino acids increased in ear bracts but not in leaves under water stress $\left[53^{\circ}\right.$, Vergara-Diaz et al. unpublished results). These changes highlight the active role of ear bracts in producing organic and amino acids for the growing grain and are in line with the high refixation rates of respiratory $\mathrm{CO}_{2}$ in these organs and the upregulation of $\mathrm{C}-\mathrm{N}$ metabolism genes. Several sugars increased in ears, which can be associated with better $\mathrm{C}$ assimilation via photosynthesis or greater breakdown of complex sugars to increase osmolytes (raffinose, trehalose, malate, maltose and isomaltose) and improve drought tolerance (Figure 2). The accumulation of most of the amino acids in ears can also indicate a better tolerance to stress. Although some components can be involved in other functions, increases in glycine, serine, glycerate and glycolate suggest that photorespiration is induced to protect ears from photoinhibition under water or heat stress. Ascorbate metabolism, which is involved in the antioxidant system, was also induced in ears. In agreement with these observations, Impa et al. $\left[54^{\circ \bullet}\right.$ ] showed an increase in proteinogenic amino acids (glycine methionine, and alanine) and carbohydrates (sucrose, glucose, fructose, myo-inositol, raffinose, and maltose) in wheat ears subjected to high night temperatures after heading, changes that were mostly not observed in leaves. Again, these changes can be related to stress-induced breakdowns or stress-adaptive processes (accumulation of osmolytes to maintain cell turgor, stabilise cell membranes, and prevent protein degradation). In barley, Hein et al. [55 ] indicated that several amino acids (glycine, valine, isoleucine, threonine, and phenylalanine) and sugars (glucose, fructose, sucrose and malate) accumulated in ear organs in response to water stress, although their changes were organ-specific. Furthermore, the combination of water and heat stress led to changes in the rice metabolome that are dependent on the cultivar, the organ and the severity of the water stress $\left[56^{\circ \bullet}\right]$. Interestingly, mild water stress did not modify the metabolome of flowering spikelets when all the cultivars were grouped together, whereas several sugars and amino acids related to stress were modified in leaves. Under severe drought, more sugars and amino acids related to stress increased in leaves compared to mild stress, while respiratory intermediates decreased. However, in spikelets severe water stress only induced a few amino acids (isoleucine, leucine and threonine) and polyols. In developing seeds water stress increased some amino acids and decreased succinic acid, glucose-6-phosphate, erythronic acid and erythritol. Proline, which is involved in stress responses as an osmolyte and antioxidative defence and signalling molecule, was generally accumulated under water stress in both leaves and ears $\left[53^{\bullet \bullet}, 55^{\circ}\right]$.

Regarding enzyme activities, we described above stimulation of ' $\mathrm{C} 4$ enzymes' that could reflect induction of organic and amino acid synthesis in ears for transport to developing grains $\left[22^{\circ}, 44,46\right]$. Additionally, Kong et al.

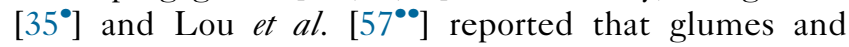
lemmas have higher antioxidant enzyme activities (their gene expression was also induced) and lower accumulation of ROS than flag leaves in wheat under water stress. Overall, the data support the idea of an active metabolism in ear organs (one that is efficiently protected against water deficit) that significantly contributes to grain filling, especially during the late stages when leaves are more senescent. In fact, the ears are the youngest photosynthetic organs and the last to develop, and as water stress progresses they show a slower decline in their photosynthetic apparatus than the leaves, which is mainly due to their better water status.

\section{Metabolic/molecular clues for improvement}

A complete understanding of the mechanisms of carbon assimilation and drought tolerance in the different ear parts is necessary for the identification of new traits as selection criteria for breeding programs. The variability in $\mathrm{CO}_{2}$ refixation between cultivars and its role in grain yield is still not well studied. This trait can positively impact grain yield by ensuring the provision of $\mathrm{CO}_{2}$ for ear photosynthesis and minimising the loss of $\mathrm{CO}_{2}$ released by grains, while ensuring a high WUE because transpiration through stomata is prevented.

Furthermore, it seems that there are differences between the genes expressed in ears and leaves $\left[47^{\bullet \bullet}, 58\right]$, which suggests that some enzyme isoforms are organ-dependent. For example, $\mathrm{C}_{4}$-specific forms of several enzymes were observed in wheat pericarps and differed from the typical $\mathrm{C}_{3}$ forms found in leaves $\left[47^{\bullet \bullet}\right.$. The conversion of $\mathrm{C}_{3}$ crops towards $\mathrm{C}_{4}$ photosynthesis is a long-standing but 
challenging goal due to the specialised anatomy of the $\mathrm{C}_{4}$ pathway, which requires further research as well as improvements to the current engineering tools to enable introduction into the $\mathrm{C}_{3}$ cereals [59]. In the shorter term, the identification of specific isozymes in ears, which can have an advantage under drought and heat stresses, are potential targets for introduction into leaf tissues. The recent advances in genome editing through CRISPR technology may greatly accelerate the engineering of cereals, even in the case of wheat with its large genome and recalcitrant nature [60]. The 'omic' studies have significantly contributed to the identification of new candidate genes, metabolites and proteins in ears that can be used in breeding programmes to improve drought and heat stress tolerance. For example, metabolites with osmolyte functions, TCA cycle intermediates, antioxidant enzymes, or stress response genes upregulated in ears can be used as target proxies to screen diverse germplasm or mapping populations to identify important genomic regions and develop gene-based markers to

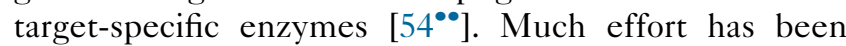
invested in studying ear carbon metabolism, yet the potential contribution of ears towards supplying nitrogen might also be a positive trait for grain yield [17]. Knowledge of the role that ears play in nitrogen assimilation, translocation and remobilisation during grain filling is still scarce, but it seems to be relevant $\left[18,29^{\bullet \bullet}\right]$.

\section{Phenotyping ears}

Many questions remain open about the mechanisms of ear photosynthesis, such as the contribution of $\mathrm{CO}_{2}$ refixed from growing grains versus that from the surrounding atmosphere, or even the photosynthetic metabolism of the different ear parts $[49,50]$ compared to laminar parts of the plant, which are crucial to understanding the adaption of the ear to stress conditions. The awns are the main photosynthetic organ in ears that fix external $\mathrm{CO}_{2}$, followed by the glumes, whereas photosynthesis in the ear bracts (i.e. lemmas and paleae) and green pericarps is mainly related to recycling respiratory $\mathrm{CO}_{2}$ $\left[12^{\bullet \bullet}, 29^{\bullet}, 41\right]$. However, the relative importance of the external and internal sources of $\mathrm{CO}_{2}$ to ear photosynthesis has not been resolved and genotypic variability may be expected. This is not trivial since, for example, an internal source of $\mathrm{CO}_{2}$ may be associated with lower photorespiration losses, while fixation of the external $\mathrm{CO}_{2}$ is related to transpiration and ear cooling, which is positive, but also a negative factor with respect to the associated water loss. Besides that, the relative contribution of both sources may change through time (basically increasing the importance of refixed $\mathrm{CO}_{2}$ ) as the grains grow and sit tightly against the internal bracts. The search for phenotypic approaches to discern the relative contribution of both sources of $\mathrm{CO}_{2}$ in the ear photosynthesis continues.

On a different level, there is not yet a high-throughput phenotyping approach to assess the photosynthetic contribution of the ear to the growth and development of wheat grains (Figure 4). The protocols available are either intrusive and/or low throughput, which has to date made ear phenotyping impractical on a large scale and in general terms only feasible for selecting parental lines for further crossings (Figure 4). In other words, the nature of these phenotypical approaches makes them difficult to upscale and to apply in genomic selection (that models markers of largely unknown effect to predict yield, and QTL) or in genome wide association studies (GWAS, that help to dissect complex physiological traits). Evidence for this is the existence of only one study that has reported the use of these techniques for GWAS [30]. Besides that, molecular markers associated with ear morphological traits such as ear length, awn length and number of spikelets per ear have been identified in wheat [61-63], barley [64] or wheat wild relatives [65]. Nevertheless, the identification of molecular markers associated with ear photosynthesis shows promise as a breeding tool for use in marker-assisted selection and would represent a step forward in the status of the ear as a photosynthetic organ.

Different remote sensing and analytical approaches are emerging that allow phenotyping of the photosynthetic performance of ears in a more high-throughput manner. For example, the use of the hydrogen stable isotope signature $\left(\delta^{2} \mathrm{H}\right)$ in its natural abundance has been proposed as an indicator of the degree of photoautotrophy in different organs of wheat (including the ear) [66 $\left.6^{\circ \circ}\right]$, in addition to its role as an indicator of transpiration and thus water status.

Moreover, as stated above, different lines of evidence suggest that higher levels of stomatal conductance and transpiration are associated with genetic advance in yield $[7,9,67]$. Therefore, it is expected that the best performing wheat genotypes will maintain ears at lower temperatures as an indicator of better water status and higher levels of ear photosynthesis. In addition, it has been proposed that ear temperature may also indicate the phenological stage and genotypic heat stress tolerance [68]. Therefore, it is necessary to develop phenotyping protocols that are able to measure ear temperature in the field while discerning it from the rest of the canopy. This may be achieved through direct measurement of ear temperature in the field using algorithms based on thermal images alone [69] or combined with high-resolution RGB images $\left[70^{\circ}\right]$, and thus could select the ears for data extraction (e.g. temperature). In this sense, the automatic extraction of specific information of a given plant part from any RGB, spectral or thermal image acquired on the ground or even from an unnamed aerial platform (e.g. drone) is already a feasible technological target. Highresolution RGB images are ideal candidates for practical large-scale implementation of remote sensing-based phenotyping of ears. The main challenges to be accomplished are the development of specific algorithms, so that RGB images can be used alone or in combination with thermal and spectral information, and then applied to analyse the 


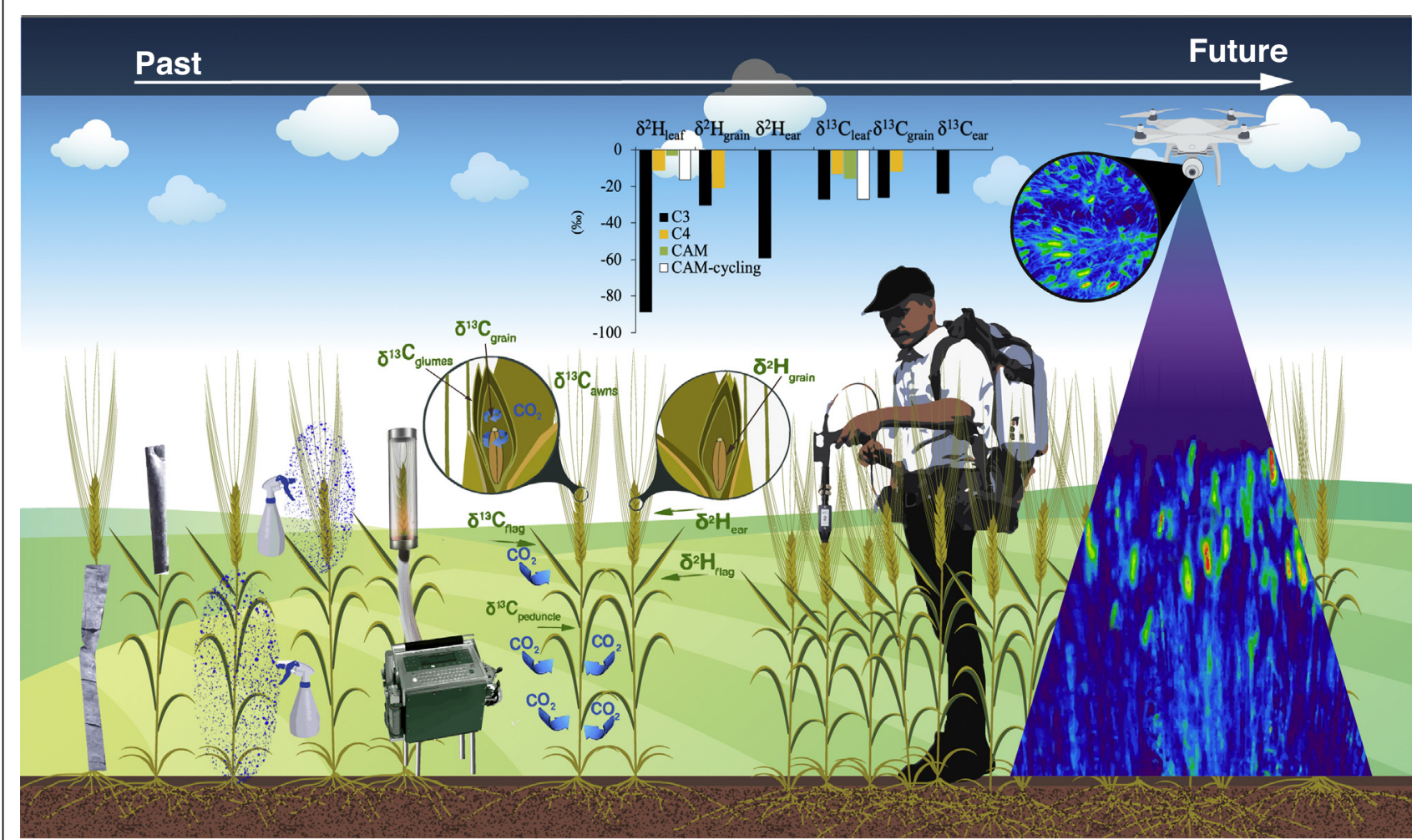

Current Opinion in Plant Biology

Different strategies for ear phenotyping have been developed over time and will continue being developed into the future. Approaches developed in the past to estimate relative contributions of the ear and other parts of the culm to grain filling include organ-specific inhibition of photosynthesis through different approaches such as: i) application of herbicides $\left[14^{\bullet}, 79\right]$, desiccants such as potassium iodide [80]; ii) shading or source/sink manipulation treatments, including organ removal [23,81-83]; and iii) an approach using the $\delta^{13} \mathrm{C}$ of assimilates that allows inference of the relative contribution of the awns, glumes and peduncle to grain filling $\left[14^{\bullet}, 15,16\right]$. The above approaches may be combined with gas exchange measurements (net and gross photosynthesis and respiration) of the ear, using specially designed photosynthetic chambers and portable gas analysers. Recently, other approaches have been proposed if not to assess the relative contribution of each plant part to grain filling, at least to characterise relevant photosynthetic attributes of the ears. This is the case of the analysis of the stable hydrogen isotope composition $\left(\delta^{2} \mathrm{H}\right)$ in its natural abundance when analysed from different plant parts such as the ear, flag leaf and mature grains [66 ${ }^{\circ}$. Thus $\delta^{2} \mathrm{H}$ may provide simultaneous time-integrated records of the photosynthetic and evaporative performance of the plant during crop development based on, among other aspects, its tighter association with $\delta^{13} \mathrm{C}$ than with $\delta^{18} \mathrm{O}\left[66^{\circ}\right]$. $\delta^{2} \mathrm{H}$ may be further strongly affected by the trophic (photoautotrophic versus heterotrophic) nature of the plant part considered [84-90], as well as being affected by potential differences in their photosynthetic metabolism. A step forward in terms of high throughput methodologies for ear phenotyping implies to explode the potential of spectroscopy for in situ (i.e. field) prediction in a non-destructive manner of the profiles of key metabolites in specific organs such as the ear bracts and the flag leaf using a portable spectroradiometer $\left[29^{\circ}, 53^{\circ}\right.$ ] . While this technique has proved feasible, it is necessary to upscale it even further in terms of high throughput. In that context it is necessary to develop-specific algorithms for image data extraction of specific plant parts such as the ear from the remaining canopy (i.e. leaves) and subsequently analysing the ear. The relevant information amenable to specific-organ extraction is colour (RGB images), temperature (thermal images) and spectral signatures (multispectral cameras). In that sense, the use of RGB images alone (to assess the ear colour) or combined (for organ detection and area profiling) with thermal and multispectral/hyperspectral images, to extract-specific information from the ears is a goal that is already technically achievable. That may allow in the near future the phenotyping of ears from canopy images acquired at ground level or from an unmanned aerial vehicle. To that end, developing algorithms for automatic ear detection [69] and further contour delimitation, preferably based on the use of high-resolution RGB images, is the step to follow. The insight histogram near the $\delta^{2} \mathrm{H}$ refer to the range of values reported for different plant parts of wheat $\left[66^{\circ}\right]$ or among species with different photosynthetic metabolism (SanchezBragado unpublished results).

colour characteristics of the ears or the definition of the contours or these organs for further extraction of thermal or spectral information. An example of a rather simple trait for phenotyping, through RGB images taken from an aerial platform, is the stay-green' attribute in the ear.
The development of high-resolution spectral systems has been promoted for quantitative estimation of plant biochemical and physiological processes. Recent studies have addressed the use of hyperspectral reflectance for the evaluation of diverse physiological traits such as 
photosystem functioning, maximum Rubisco activity and dark respiration [71-73]. In contrast, close relationships between the plant metabolome, yield performance and stress resilience have been reported $\left[53^{\bullet \bullet}, 74\right]$. In this sense, the possibility of predicting certain leaf and ear metabolites from remotely sensed data, particularly under field conditions, might enable in vivo metabolomics (metabolite characterisation) and open the door to a new generation of plant phenotyping approaches. Developing prediction models in metabolites of ear tissues using hyperspectral information has already been reported [53 $3^{\circ}$. However, its implementation as a high throughput technique in the field, either using sensors or imagers, is necessary if hyperspectral measurements are to be adopted as a phenotyping technique. It is in this context that the integration of organ recognition algorithms for data extraction from the canopy makes becomes relevant.

\section{Concluding remarks}

The cereal inflorescence has particular characteristics that overpass the traditional perception of a sink organ where grains are formed. In that sense, inflorescence photosynthesis (and in the case of wheat or barley, ear photosynthesis) plays a key role in determining yield during the last part of the crop cycle. The identification in the field of lines with higher ear photosynthesis rates and/or contributions to filling the grains, the reasonably heritability values of these traits, their correlation with yield or yield component and new phenotypic techniques to determine the contribution of ear photosynthesis towards grain yield will justify the inclusion of this photosynthetic organ in breeding programs.

\section{Declaration of interests}

The authors declare that they have no known competing financial interests or personal relationships that could have appeared to influence the work reported in this paper.

\section{Acknowledgements}

This work was supported in part by the project AGL2016-76527-R from MINECO, Spain.

We thank Dr Eduardo Tambussi for his valuable comments on the draft manuscript. RSB was supported by Juan de la Cierva program JDCFormación (FJCI-2016-28164). JLA acknowledges the Support from ICREA Acadèmia, 1006 Govern of Catalonia, Spain.

\section{References and recommended reading}

Papers of particular interest, published within the period of review, have been highlighted as:

- of special interest

$\bullet$ of outstanding interest

1. Chairi F, Vergara Diaz O, Vatter T, Aparicio N, Nieto-Taladriz MT, Kefauver SC, Bort J, Serret MD, Araus JL: Post-Green Revolution genetic advance in durum wheat: the case of Spain. Field Crop Res 2018, 228:158-169.
2. Crespo-Herrera LA, Crossa J, Huerta-Espino J, Vargas M, Mondal S, Velu G, Payne TS, Braun H, Singh RP: Genetic gains for grain yield in CIMMYT's semi-arid wheat yield trials grown in suboptimal environments. Crop Sci 2018, 58:1890-1898.

3. Fischer RA, Byerlee D, Edmeades GO: Crop yields and global food security: will yield increase continue to feed the world? ACIAR Monograph 158. Australian Centre for International Agricultural Research; 2014.

4. Driever SM, Simkin AJ, Alotaibi S, Fisk SJ, Madgwick PJ, Sparks CA, Jones HD, Lawson T, Parry MA, Raines CA: Increased SBPase activity improves photosynthesis and grain yield in wheat grown in greenhouse conditions. Philos Trans $R$ Soc B: Biol Sci 2017, 372:20160384.

5. Simkin AJ, López-Calcagno PE, Raines CA: Feeding the world: improving photosynthetic efficiency for sustainable crop production. J Exp Bot 2019, 70:1119-1140.

6. Araus JL, Serret MD, Lopes MS: Transgenic solutions to increase yield and stability in wheat: shining hope or flash in the pan? J Exp Bot 2019, 70:1419-1424.

7. Roche D: Stomatal conductance is essential for higher yield potential of $\mathbf{C}_{3}$ crops. Crit Rev Plant Sci 2015, 34:429-453.

8. Carmo-Silva E, Andralojc PJ, Scales JC, Driever SM, Mead A, Lawson T, Raines CA, Parry MA: Phenotyping of field-grown wheat in the UK highlights contribution of light response of photosynthesis and flag leaf longevity to grain yield. J Exp Bot 2017, 68:3473-3486.

9. Chairi F, Sanchez-Bragado R, Serret MD, Aparicio N, NietoTaladriz MT, Araus JL: Agronomic and physiological traits related to the genetic advance of semi-dwarf durum wheat: the case of Spain. Plant Sci 2019:110210. (in press).

10. Murchie E, Kefauver S, Araus JL, Muller O, Rascher U, Flood PJ, Lawson T: Measuring the dynamic photosynthome. Ann Bot 2018, 122:207-220.

11. Inoue T, Inanaga S, Sugimoto $Y, A n P$, Eneji AE: Effect of drought on ear and flag leaf photosynthesis of two wheat cultivars differing in drought resistance. Photosynthetica 2004, 42:559-565.

12. Tambussi EA, Bort J, Guiamet JJ, Nogués S, Araus JL: The

- $\quad$ photosynthetic role of ears in $\mathrm{C}_{3}$ cereals: metabolism, water use efficiency and contribution to grain yield. Crit Rev Plant Sci 2007, 26:1-16

The first comprehensive and exhaustive review about ear photosynthesis, including its potential contribution to the grain yield in $\mathrm{C}_{3}$ cereals such as wheat and barley, the refixation capacity (i.e. re-assimilation of respired $\left.\mathrm{CO}_{2}\right)$, the type of photosynthetic metabolism $\left(\mathrm{C}_{3}\right.$ versus $\left.\mathrm{C}_{4}\right)$, water use efficiency and the tolerance to water and heat stress.

13. Maydup ML, Antonietta M, Guiamet JJ, Tambussi EA: The

- contribution of green parts of the ear to grain filling in old and modern cultivars of bread wheat (Triticum aestivum L.): evidence for genetic gains over the past century. Field Crop Res 2012, 134:208-215

A retrospective study, exploring how the ear contribution to grain filling has changed in bread wheat across the history of wheat breeding in Argentina. It is the first report that shows an increase in the ear contribution throughout the course of breeding in a historical series. It is proposed that the introduction of semi-dwarf alleles during the Green Revolution could have increased the ear contribution in plants with shorter and lighter stems.

14. Sanchez-Bragado R, Molero G, Reynolds MP Araus JL:

- Photosynthetic contribution of the ear to grain filling in wheat: a comparison of different methodologies for evaluation. J Exp Bot 2016, 67:2787-2798 http://dx.doi.org/10.1093/jxb/erw116 The relative contribution of the ear to grain filling in bread wheat was assessed using three different methodologies. Two of them consisted of a targeted inhibition of photosynthesis by a herbicide or shading and the third one included an approach based on the $\delta^{13} \mathrm{C}$ of assimilates. The three methodologies assigned a similar or even a greater contribution of the ear to grain filling compared to the culm.

15. Sanchez-Bragado R, Elazab A, Zhou B, Serret MD, Bort J, NietoTaladriz MT, Araus JL: Contribution of the ear and the flag leaf to grain filling in durum wheat inferred from the carbon isotope signature: genotypic and growing conditions effects. J Integr Plant Biol 2014, 56:444-454. 
16. Sanchez-Bragado R, Molero G, Reynolds M, Araus JL: Relative contribution of shoot and ear photosynthesis to grain filling in wheat under good agronomical conditions assessed by differential organ $\delta 13 C$. J Exp Bot 2014, 65:5401-5413.

17. Sanchez-Bragado R, Serret MD, Araus JL: The nitrogen contribution of different plant parts to wheat grains: exploring genotype, water, and nitrogen effects. Front Plant Sci 2017, 7:1986

18. Lopes MS, Cortadellas N, Kichey T, Dubois F, Habash DZ, Araus JL: Wheat nitrogen metabolism during grain filling: comparative role of glumes and the flag leaf. Planta 2006 225:165-181.

19. Hosseini SM, Poustini K, Siddique KHM, Palta JA: Photosynthesis of barley awns does not play a significant role in grain yield under terminal drought. Crop Pasture Sci 2012, 63:489-499.

20. Araus JL, Brown HR, Febrero A, Bort J, Serret MD: Ear

- photosynthesis, carbon isotope discrimination and the contribution of respiratory $\mathrm{CO}_{2}$ to differences in grain mass in durum wheat. Plant Cell Environ 1993, 16:383-392

One of the founder studies highlighting the importance of ear photosynthesis in grain yield, including the notion of refixation of $\mathrm{CO}_{2}$, the xeromorphic characteristics of the glumes and the water use efficiency of the ear and the existence of genotypic variability in photosynthetic rates.

21. Blum A: Photosynthesis and transpiration in leaves and ears of - wheat and barley varieties. J Exp Bot 1985, 36:432-440 The first publication that stressed the potential importance of ear photosynthesis in wheat performance, and particularly under stress conditions. Even though this work was undertaken in detached ears and leaves it is a pioneering study including gas exchange data.

22. Jia S, Lv J, Jiang S, Liang T, Liu C, Jing Z: Response of wheat ear - $\quad$ photosynthesis and photosynthate carbon distribution to water deficit. Photosynthetica 2015, 53:95-109

The photosynthetic contribution of the ear to grain filling of bread wheat was demonstrated, together with the changes in enzyme activities related to $\mathrm{CO}_{2}$ assimilation under water stress in a pot experiment.

23. Maydup ML, Antonietta M, Guiamet JJ, Graciano C, López JR, Tambussi EA: The contribution of ear photosynthesis to grain filling in bread wheat (Triticum aestivum L.). Field Crop Res 2010, 119:48-58.

24. Abbad H, El Jaafari S, Bort J, Araus JL: Comparison of flag leaf and ear photosynthesis with biomass and grain yield of durum wheat under various water conditions and genotypes. Agronomie 2004, 24:19-28.

25. Maydup ML, Antonietta M, Graciano C, Guiamet JJ, Tambussi EA: The contribution of the awns of bread wheat (Triticum aestivum L.) to grain filling: responses to water deficit and the effects of awns on ear temperature and hydraulic conductance. Field Crop Res 2014, 167:102-111.

26. Aranjuelo I, Cabrera-Bosquet L, Morcuende R, Avice JC, Nogués S, Araus JL, Martínez-Carrasco R, Pérez P: Does ear C sink strength contribute to overcoming photosynthetic acclimation of wheat plants exposed to elevated $\mathrm{CO}_{2}$ ? J Exp Bot 2011, 62:3957-3969.

27. Zhou B, Serret MD, Elazab A, Pie JB, Araus JL, Aranjuelo I, SanzSaez A: Wheat ear carbon assimilation and nitrogen remobilization contribute significantly to grain yield. J Integr Plant Biol 2016, 58:914-926.

28. Zheng H, Wang X, Li Y, Huang G, Tang Q, Tang J: Contributions of photosynthetic organs to the seed yield of hybrid rice: the effects of gibberellin application examined by carbon isotope technology. Seed Sci Technol 2018, 46:533-546.

29. Vicente R, Vergara-Díaz O, Medina S, Chairi F, Kefauver SC

- Bort J, Serret MD, Aparicio N, Araus JL: Durum wheat ears perform better than the flag leaves under water stress: gene expression and physiological evidence. Environ Exp Bot 2018, 153:271-285

Describes the changes at the physiological level and for the expression of key genes related to primary metabolism and the drought-stress response between flag leaves and ears in four cultivars of field-grown durum wheat. The study provides evidence that the ear is better adapted to stress conditions than the flag leaf.
30. Molero G, Reynolds M: Spike photosynthesis as a selection criterion in wheat breeding. Genotypic variation and high throughput screening. Field Crop Res 2019. (accepted).

31. Burgess AJ, Retkute R, Preston SP, Jensen OE, Pound MP, Pridmore TP, Murchie EH: The 4-dimensional plant: effects of wind-induced canopy movement on light fluctuations and photosynthesis. Front Plant Sci 2016, 7:1392.

32. Taylor SH, Long SP: Slow induction of photosynthesis on shade to sun transitions in wheat may cost at least $21 \%$ of productivity. Philos Trans R Soc B: Biol Sci 2017 372:20160543.

33. Febrero A, Fernández S, Molina-Cano JL, Araus JL: Yield, carbon isotope discrimination, canopy reflectance and cuticular conductance of barley isolines of differing glaucousness. J Exp Bot 1998, 49:1575-1581.

34. Ding H, Liu D, Liu X, Li Y, Kang J, Lv J, Wang G: Photosynthetic and stomatal traits of spike and flag leaf of winter wheat (Triticum aestivum L.) under water deficit. Photosynthetica 2018, 56:687-697.

35. Kong L, Sun M, Xie Y, Wang F, Zhao Z: Photochemical and

- antioxidative responses of the glume and flag leaf to seasonal senescence in wheat. Front Plant Sci 2015, 6:358

Comprehensive description of the photochemical and antioxidative responses of glumes and flag leaves in field-grown bread wheat during grain filling, including analyses of the anatomy, stomatal density, chlorophyll fluorescence, pigments, activity of antioxidant enzymes and quantification of reactive oxygen species.

36. Martinez DE, Luquez VM, Bartoli CG, Guiamet JJ: Persistence of photosynthetic components and photochemical efficiency in ears of water-stressed wheat (Triticum aestivum). Physiol Plantarum 2003, 119:519-525.

37. Tambussi EA, Nogues S, Araus JL: Ear of durum wheat under water stress: water relations and photosynthetic metabolism. Planta 2005, 221:446-458.

38. Blum A: The effect of heat stress on wheat leaf and ear photosynthesis. J Exp Bot 1986, 37:111-118.

39. Morgan JM: Osmotic adjustment in the spikelets and leaves of wheat. J Exp Bot 1980, 31:655-665.

40. Araus JL, Santiveri P, Bosch-Serra D, Royo C, Romagosa I: Carbon isotope ratios in ear parts of triticale: influence of grain filling. Plant Physiol 1992, 100:1033-1035.

41. Bort J, Brown $\mathrm{RH}$, Araus $\mathrm{JL}$ : Refixation of respiratory $\mathrm{CO}_{2}$ in the ears of $\mathbf{C}_{3}$ cereals. J Exp Bot 1996, 47:1567-1575.

42. Kriedemann P: The photosynthetic activity of the wheat ear. Ann Bot 1966, 30:349-363.

43. Gebbing $\mathrm{T}$, Schnyder $\mathrm{H}$ : $13 \mathrm{C}$ labelling kinetics of sucrose in glumes indicates significant refixation of respiratory $\mathrm{CO}_{2}$ in the wheat ear. Aust J Plant Physiol 2001, 28:1047-1053.

44. Li XZ, Hou J, Bai K, Zang X, Lin J, Li Z, Kuang T: Activity and distribution of carbonic anhydrase in leaf and ear parts of wheat (Triticum aestivum L.). Plant Sci 2004, 166:627-632.

45. Ziegler-Jons A: Gas-exchange of ears of cereals in response to carbon dioxide and light: II. Occurrence of a $\mathrm{C}_{3}-\mathrm{C}_{4}$ intermediate type of photosynthesis. Planta 1989, 178:164-175

46. Singal $H B$, Sheoran IS, Singh R: In vitro enzyme activities and products of ${ }^{14} \mathrm{CO}_{2}$ assimilation in flag leaf and ear parts of wheat (Triticum aestivum L.). Photosynth Res 1986, 8:113-122.

47. Rangan $P$, Furtado $A$, Henry RJ: New evidence for grain specific -. C4 photosynthesis in wheat. Sci Rep 2016, 6:31721

A comprehensive RNA-Seq analysis of bread wheat seeds showing the expression of a complete set of genes encoding enzymes necessary for C4 photosynthesis.

48. Araus JL, Bort J, Brown RH, Bassett CL, Cortadellas N: Immunocytochemical localization of phosphoenolpyruvate carboxylase and photosynthetic gas-exchange characteristics in ears of Triticum durum Desf. Planta 1993 191:507-514. 
49. Bort J, Brown $\mathrm{RH}$, Araus JL: Lack of $\mathbf{C}_{4}$ photosynthetic metabolism in ears of $\mathbf{C}_{3}$ cereals. Plant Cell Environ 1995, 18:697-702.

50. Busch FA, Farquhar GD: Poor evidence for $\mathbf{C}_{4}$ photosynthesis in the wheat grain. Plant Physiol 2016, 172:1357.

51. Henry RJ, Rangan P, Furtado A, Busch FA, Farquhar GD: Does $\mathbf{C}_{4}$ photosynthesis occur in wheat seeds? Plant Physiol 2017, 174:1992-1995.

52. Abebe T, Melmaiee K, Berg V, Wise RP: Drought response in the - $\quad$ spikes of barley: gene expression in the lemma, palea, awn, and seed. Funct Integr Genomics 2010, 10:191-205

A transcriptome analysis in barley comparing the differences in the response of the lemmas, paleae, awns and seeds to water stress.

53. Vergara-Diaz O, Vatter T, Kefauver SC, Obata T, Fernie A,

- Araus JL: Assessing durum wheat ear and leaf metabolomes in the field through hyperspectral data. Plant $J 2019$ http://dx.doi. org/10.1111/tpj.14636. (in press)

Hyperspectral data are gaining traction in the plant sciences, offering a rapid and non-destructive means of predicting key traits of relevance for crop breeders. The paper presents an analysis of hyperspectral data for the prediction of plant metabolites and grain yield. Of novelty here is the use of hyperspectral reflectance data taken from wheat ears to assess the profile of metabolites and the contribution of these spectral data to yield predictions.

54. Impa SM, Sunoj VSJ, Krassovskaya I, Bheemanahalli R, Obata T,

- J Jagadish SVK: Carbon balance and source-sink metabolic changes in winter wheat exposed to high night-time temperature. Plant Cell Environ 2019, 42:1233-1246

A novel study investigating the effects of high nighttime temperature on a bread wheat metabolite profile that highlights the different pattern of changes found between ears and leaves.

55. Hein JA, Sherrard ME, Manfredi KP, Abebe T: The fifth leaf and - $\quad$ spike organs of barley (Hordeum vulgare L.) display different physiological and metabolic responses to drought stress. BMC Plant Biol 2016, 16:248

Describes the changes in water status (relative water content, osmotic potential and osmotic adjustment), photosynthetic rate and metabolite content in leaves, awns, lemmas and paleae of barley plants under water stress.

56. Lawas LMF, Li X, Erban A, Kopka J, Jagadish SVK, Zuther E,

-• Hincha DK: Metabolic responses of rice cultivars with different tolerance to combined drought and heat stress under field conditions. GigaSci 2019, 8

An excellent example of the power of metabolomics for the identification of potential marker metabolites for yield stability and grain quality using rice cultivars with different drought and heat tolerance under water stress in field trials.

57. Lou L, Li X, Chen J, Li Y, Tang Y, Lv J: Photosynthetic and

-. ascorbate-glutathione metabolism in the flag leaves as compared to spikes under drought stress of winter wheat (Triticum aestivum L.). PLoS One 2018, 13:e0194625

An excellent case study for bread wheat linking the better photosynthetic stability under drought stress of the ears compared to flag leaves with a lower accumulation of reactive oxygen species and the better antioxidant system at the transcript and enzyme levels.

58. Abebe T, Skadsen RW, Kaeppler HF: Cloning and identification of highly expressed genes in barley lemma and palea. Crop Sci 2004, 44:942-950.

59. Schuler ML, Mantegazza O, Weber AP: Engineering $\mathbf{C}_{4}$ photosynthesis into $C_{3}$ chassis in the synthetic biology age. Plant J 2016, 87:51-65.

60. Khan S, Anwar S, Yu S, Sun M, Yang Z, Gao ZQ: Development of drought-tolerant transgenic wheat: achievements and limitations. Int J Mol Sci 2019, 20.

61. Sourdille P, Cadalen T, Gay G, Gill B, Bernard M: Molecular and physical mapping of genes affecting awning in wheat. Plant Breed 2002, 121:320-324.

62. Guo Z, Schnurbusch T: Costs and benefits of awns. J Exp Bot 2016, 67:2533-2535.

63. Molero G, Joynson R, Pinera-Chavez FJ, Gardiner L, RiveraAmado C, Hall A, Reynolds MP: Elucidating the genetic basis of biomass accumulation and radiation use efficiency in spring wheat and its role in yield potential. Plant Biotechnol J 2019: $1-13$.

64. Maurer A, Draba V, Pillen K: Genomic dissection of plant development and its impact on thousand grain weight in barley through nested association mapping. J Exp Bot 2016, 67:2507-2518.

65. Liu Y, Wang L, Mao S, Liu K, Lu Y, Wang J, Wei Y, Zheng Y: Genome-wide association study of 29 morphological traits in Aegilops tauschii. Sci Rep 2015, 5:15562.

66. Sanchez-Bragado R, Serret MD, Marimon RM, Bort J, Araus JL:

-• The hydrogen isotope composition $\delta 2 \mathrm{H}$ reflects plant performance. Plant Physiol 2019, 180:793-812

This is a pioneer study on the use of $\delta^{2} \mathrm{H}$ to estimate plant performance in a $\mathrm{C}_{3}$ cereal like durum wheat. $\delta^{2} \mathrm{H}$ exhibited-specific features that informed about the water conditions of the crop as well as the level of photoautotrophy or even the nature of the photosynthetic metabolism.

67. Medina S, Vicente R, Nieto-Taladriz MT, Aparicio N, Chairi F, Vergara-Diaz O, Araus JL: The plant-transpiration response to vapor pressure deficit (VPD) in Durum Wheat is associated with differential yield performance and specific expression of genes involved in primary metabolism and water transport. Front Plant Sci 2018, 9:1994.

68. Steinmeyer FT, Lukac M, Reynolds MP, Jones HE: Quantifying the relationship between temperature regulation in the ear and floret development stage in wheat (Triticum aestivum L.) under heat and drought stress. Funct Plant Biol 2013, 40:700707.

69. Fernandez-Gallego JA, Buchaillot M, Aparicio Gutiérrez N, NietoTaladriz MT, Araus JL, Kefauver SC: Automatic wheat ear counting using thermal imagery. Remote Sens 2019, 11:751.

70. Fernandez-Gallego JA, Aparicio-Gutierrez N, Nieto-Taladriz MT,

- Araus JL: Wheat ear counting in-field conditions: high throughput and low-cost approach using RGB images. Plant Methods 2018, 14:22

The first report in the literature about a system for automatic detection (and further quantification) of the ears within a canopy using natural light conditions in the field. It demonstrates the capacity of the high resolution RGB images acquired from conventional digital cameras.

71. Lobos GA, Escobar-Opazo A, Estrada F, Romero-Bravo S, Garriga M, del Pozo A, Poblete-Echeverría C, Gonzalez-Talice J, González-Martinez L, Caligari P: Spectral reflectance modeling by wavelength selection: studying the scope for blueberry physiological breeding under contrasting water supply and heat conditions. Remote Sens 2019, 11:329.

72. Coast O, Shah S, Ivakov A, Gaju O, Wilson PB, Posch BC, Bryant CJ, Negrini ACA, Evans JR, Condon AG, Silva-Pérez V: Predicting dark respiration rates of wheat leaves from hyperspectral reflectance. Plant Cell Environ 2019, 42:21332150.

73. Silva-Perez V, Molero G, Serbin SP, Condon AG, Reynolds MP, Furbank RT, Evans JR: Hyperspectral reflectance as a tool to measure biochemical and physiological traits in wheat. $J$ Exp Bot 2018, 69:483-496.

74. Obata T, Witt S, Lisec J, Palacios-Rojas N, Florez-Sarasa I, Yousfi S, Araus JL, Cairns JE, Fernie AR: Metabolite profiles of maize leaves in drought, heat, and combined stress field trials reveal the relationship between metabolism and grain yield. Plant Physiol 2015, 169:2665-2683.

75. Blum A, Mayer J, Golan G: The effect of grain number per ear (sink size) on source activity and its water-relations in wheat. $J$ Exp Bot 1988, 39:106-114.

76. Tiedemann AV, Firsching $\mathrm{KH}$ : Interactive effects of elevated ozone and carbon dioxide on growth and yield of leaf rustinfected versus non-infected wheat. Environ Pollut 2000, 108:357-363.

77. Robert C, Bancal MO, Ney B, Lannou C: Wheat leaf photosynthesis loss due to leaf rust, with respect to lesion development and leaf nitrogen status. New Phytol 2005, $165: 227-241$.

78. Knoppik D, Selinger H, Ziegler-Jöns A: Differences between the flag leaf and the ear of a spring wheat cultivar (Triticum 
12 AGRI

aestivum cv. Arkas) with respect to the $\mathrm{CO}_{2}$ response of assimilation, respiration and stomatal conductance. Physiol Plant 1986, 68:451-457

79. Yamaguchi S, Crafts A: Comparative studies with labeled herbicides on woody plants. Hilgardia 1959, 29:171-204.

80. Saeidi M, Moradi F, Jalali-Honarmand S: The effect of post anthesis source limitation treatments on wheat cultivars under water deficit. Aust J Crop Sci 2012, 6:1179-1187.

81. Aggarwal PK, Fischer RA, Liboon SP: Source-sink relations and effects of postanthesis canopy defoliation in wheat at low latitudes. J Agric Sci 1990, 114:93-99.

82. Chanishvili SS, Badridze GS, Barblishvili TF, Dolidze MD: Defoliation, photosynthetic rates, and assimilate transport in grapevine plants. Russ J Plant Physiol 2005, 52:448-453.

83. Ahmadi $A$, Joudi $M$, Janmohammadi $M$ : Late defoliation and wheat yield: little evidence of post-anthesis source limitation. Field Crop Res 2009, 113:90-93.

84. Yakir D: Variations in the natural abundance of oxygen-18 and deuterium in plant carbohydrates. Plant Cell Environ 1992 15:1005-1020.
85. Farquhar GD, Lloyd J: Carbon and oxygen isotope effects in the exchange of carbon dioxide between terrestrial plants and the atmosphere. In Stable Isot. Plant CarbonWater Relations. Edited ఉy-Z10l.eringer A, Hal J, Farquhar G. San Diego: Academic P.; 1993:

86. Pande $P$, Datta $P$, Bhattacharya S: Biphasic enrichment of $\mathbf{H}_{2}{ }^{18} \mathrm{O}$ in developing wheat grain water. Indian J Exp Biol 1994, 37: 30-31.

87. Sessions AL, Burgoyne TW, Schimmelmann A, Hayes JM: Fractionation of hydrogen isotopes in lipid biosynthesis. Org Geochem 1999, 30:1193-1200.

88. Hayes JM: Fractionation of carbon and hydrogen isotopes in biosynthetic processes. Rev Mineral Geochem 2001, 43:225277.

89. Cernusak LA, Barbour MM, Arndt SK, Cheesman AW, English NB, Feild TS, Helliker BR, Holloway-Phillips MM, Holtum JAM, Kahmen $A$ et al:: Stable isotopes in leaf water of terrestrial plants. Plant Cell Environ 2016, 39:1087-1102.

90. Cormier MA, Werner RA, Sauer PE, Gröcke DR, Leuenberger MC Wieloch T, Schleucher J, Kahmen A: ${ }^{2} \mathrm{H}$-fractionations during the biosynthesis of carbohydrates and lipids imprint a metabolic signal on the $\mathrm{d}^{2} \mathrm{H}$ values of plant organic compounds. New Phytol 2018, 218:479-491. 